\title{
Relationship between quality of life and clinical status in patients with gastrointestinal cancer
}

\author{
Ricardo Sánchez ${ }^{1,2}$, Fabio Alexander-Sierra ${ }^{1}$ and Ricardo Oliveros ${ }^{3}$ \\ ${ }^{\prime}$ Clinical Research Group. National Institute of Oncology. Bogotá, Colombia. ${ }^{2}$ Department of Medicine. National \\ University of Colombia. ${ }^{3}$ Gastrointestinal Surgery and Digestive Endoscopy Group. National Institute of Oncology. \\ Bogotá, Colombia
}

\begin{abstract}
Background: previous studies with patients having cancer have shown that quality of life scores depend on the clinical stage of the disease (the more advanced the disease, the worst quality of life).

Methods: in a prospective study we studied 317 patients with gastric or colorectal cancer attending the Instituto Nacional de Cancerología between 2010 and 2011; the patients completed the EORTC QLQ-C30 before receiving treatment. This instrument measures quality of life in 15 domains. Scores of each domain were compared according to tumor stage. Differential Item Functioning was measured across neoplasm staging and tumor localization.

Results: 145 patients (45.7\%) were diagnosed with colorectal cancer. According to clinical staging, differences in quality of life scores were observed in 4 of 15 domains (physical and social functioning, anorexia). Most of the differences in quality of life domains depended on tumor localization (patients with colorectal cancer had the highest scores in quality of life) and sex (women reported better scores). These differences seemed to be independent of item properties. The construct was more adequately measured with items that explore the construct using a general approach.

Conclusion: in this group of patients with colorectal and gastric cancer quality of life scores were more related with tumor localization than with clinical stage.
\end{abstract}

Key words: Quality of life. Outcome assessment (Health Care). Neoplasms. Age groups.

Sánchez R, Alexander-Sierra F, Oliveros R. Relationship between quality of life and clinical status in patients with gastrointestinal cancer. Rev Esp Enferm Dig 2012;104:584-591.

Received: $30-08-2012$

Accepted: 19-11-2012

Correspondence: Ricardo Sánchez. Instituto Nacional de Cancerología. Avenida 1a, n. ${ }^{\circ}$ 9-85. Bogotá, D.C. Colombia

e-mail: rsanchezpe@unal.edu.co

\section{INTRODUCTION}

Health related quality of life is a subjective, dynamic, and multidimensional concept that has become such an important issue in chronic diseases that it is now considered indicative of healthcare quality (1). This adjustment seems to be related to the increasing recognition of the social implication of disease (2) and to the increased life expectancy of patients suffering from chronic diseases (3). In patients with cancer, measuring quality of life may serve to rate the efficiency of therapeutic interventions $(4,5)$.

The primary subjective component of the concept of quality of life is reflected by the seemingly contradictory results obtained when measuring quality of life in specific populations, e.g., findings that patients who were more disabled had a better quality of life, and vice versa, have led to the idea of the "disability paradox" $(6,7)$. This idea has also been applied to patients with cancer because these patients reported a better quality of life than those who attended family planning counseling (8).

Despite the recognized subjectivity of the concept, methods that claim to measure quality of life in a valid and reliable way have been developed on the basis that the process could focus more on the patient's perception than on the signs and symptoms of the disease (9). The available measuring instruments can be grouped into two categories: instruments specific to conditions, which measure quality of life in a global way, regardless of the type of cancer, e.g., the EORTC QLQ C30 scale $(10,11)$, and instruments specific to the disease, which incorporate the specific features of a given type of tumor, e.g., the EORTC CR29 (12) and EORTC STO 22 (13), which respectively measure quality of life in patients with gastric and colorectal cancer. These instruments include a multidimensional scheme, where symptoms, functional capacity, social role, and the emotional component are evaluated as distinct domains. However, the ability of these domains to comprehensively reflect the structure of the concept has been questioned. For 
instance, one study reported that the aspect that had the greatest impact on quality of life in a group of patients was the availability of parking spots when they came to a medical appointment (14). Moreover, some authors have suggested that community aspects should be given more weight when measuring quality of life (15); others consider that religiosity and spirituality are the central components of the concept (16). In addition, other studies have shown that access to healthcare systems can be a key factor in determining quality of life related to health (17).

These previous investigations raised the question of whether the available instruments and scales assessing quality of life measured what researchers, professionals, or society consider quality of life for an individual with a disease or what patients consider most important (18), which may not always coincide.

\section{METHODS}

According to previous publications, quality of life generally depends on clinical status, such that quality of life decreases with disease severity $(19,20)$. We therefore conducted this study with the goal of establishing whether clinical status is linked to differences in quality of life in patients with colorectal or stomach cancer and to what extent certain items on the commonly used EORTC QLQ C30 scale can serve to distinguish levels of quality of life related to health. We selected patients with gastrointestinal cancer because it is one of the most common malignant pathologies in the world. According to data from Globocan (2008), gastric cancer was the second most common cancer affecting men worldwide and ranked first in terms of deaths; among women, gastric cancer ranked third in terms of both frequency and mortality (21). In , gastric cancer is the leading cause of death from cancer, and colorectal cancer is the fifth leading cause (22). These two types of cancer were selected not only because of the frequency of the pathologies in but also because the location of the tumor might explain some of the potential differences in quality of life scores. Analyses linking quality of life and clinical status should therefore incorporate this factor.

\section{Participants}

The EORTC QLQ C30 quality of life scale was applied to a total of 317 adult patients diagnosed with gastric or colorectal cancer and assessed in the Gastroenterology outpatient service of the National Oncology Institute of Bogotá between 2010 and 2011. These patients were selected consecutively as a non-probabilistic sample in a prospective recruitment process according to the defined eligibility criteria: elderly patients with a confirmed diagnosis of gastric or colorectal cancer, with complete and available staging information, who had not yet started treatment, who were able to read and write, and who were willing to participate in the study. A research assistant trained in the use and processing of the instrument advised each patient until completion.

\section{Instrument}

The EORTC QLQ C30 questionnaire is a tool used to measure quality of life that consists of 30 items rated on a 1 to 4 scale (two questions are rated between 1 and 7). The items comprise 15 domains, many of which address physical symptoms: general health status, physical functioning, functional role, emotional functioning, cognitive functioning, social functioning, fatigue, nausea/vomiting, pain, dyspnea, insomnia, lack of appetite, constipation, diarrhea, and financial problems. This instrument has been translated and transculturally adapted for use in (23). A sample can be downloaded at the following URL: http://groups.eortc.be/qol/eortc-qlq-c30, and versions in various Spanish dialects can be requested.

\section{Statistical analysis}

Regarding the initial description of the variables, we used means and standard deviations (SD) for continuous variables and frequencies and percentages for categorical variables. Comparisons were performed for the different cancer types using variables such as sex, age, education level, and clinical status. Student's t-test, $\chi^{2}$ test, or Fisher's exact test were used depending on the nature of the variables or the structure of the contingency tables. The scores for each domain of the scale were compared across clinical stages, adjusting the comparison according to the location of the tumor (stomach or colon/rectum), sex, and education level. For these comparisons, we used multiple regression models, where the dependent variable was the score of the scale in the respective domain, and the independent variables were clinical stage, tumor location, sex, and education level. For the regression model, clinical status was divided into four levels and used as an indicative variable, taking stage I as the reference. Education level was also used as an indicative variable under the following levels: none, primary, secondary, and college (the latter was used as the reference category). To test the hypotheses presented in the analysis, we used a 5\% significance level, and the analyses were conducted using the Stata $12 \circledR$ program. To identify the items most likely to detect potential differences, an analysis of differential item functioning (DIF) was conducted based on a Rasch model; according to this model, the probability of a response to the items on the questionnaire should be higher among patients who exhibit a higher level of the attribute (quality of life in this case), regardless of the subgroup to which they belong. Thus, all patients with a high quality of life should be more likely to have high scores for the various items, regardless of the location of the cancer. Similarly, assuming that patients at advanced stages have a worse quality of life, differential functioning 
should be found when the data are stratified by clinical status. To conduct this analysis, a staging series that grouped patients into two categories (I to IIA $v s$. IIB to IV) was generated. Biases were detected in items by calculations and graphical analysis of the t-statistic $(24,25)$. The role of each item was compared with the structure of the sample using a person-items map. The analyses related to the Rasch models were conducted with Winsteps ${ }^{\circledR}$ software.

This paper presents the results of two projects on validation of quality of life scales that were approved by the Committee of Ethics of the National Institute of Oncology.

\section{RESULTS}

A total of 317 patients with colorectal or gastric cancer were evaluated, 145 of whom $(45.7 \%)$ were diagnosed with colorectal cancer. The mea age was 58.2 years $(\mathrm{SD}=12.7$ years) for the colorectal cancer patient group and 60 years $(\mathrm{SD}=14.6$ years) for the gastric cancer group $(\mathrm{p}>0.05)$. The group of colorectal cancer patients included 67 women $(46.2 \%)$, whereas the gastric cancer group contained 76 women $(44.2 \%)(p>0.05)$. Regarding education levels, the proportion of patients with a high level of schooling was significantly greater in the group with colorectal cancer than in the group with gastric cancer (Fisher's exact test, $p$ $<0.001$ ) (Table I). No significant difference in clinical status was noted according to the location of the cancer (Table II).

The scores obtained in each domain of the scale, organized according to tumor location and clinical status, are presented in table III. In general, the colorectal cancer patients reported a better quality of life, showing higher scores in the evaluation of performance and lower scores for symptoms. After controlling for sex, education level, and tumor location, the regression models indicated that clinical status influenced quality of life scores only for the physical and social functioning and lack of appetite domains (Tables IV and V). Proceeding from clinical stage I to IV reduced the physical performance score by 10.5 units $(\mathrm{t}=$ $-2.45, p=0.015 ; 95 \%$ confidence interval: -2.1 to -18.9$)$ and the social performance score by 12.6 units $(t=-2.38$,

Table I. Distribution of patients according to education level and type of cancer

\begin{tabular}{lcccc}
\hline \multirow{2}{*}{ Level of schooling } & Colorectal & Gastric & Total \\
\cline { 2 - 5 } None & $\mathrm{n}$ & 3 & 17 & 20 \\
\multirow{2}{*}{ Primary } & $\%$ & 2.2 & 9.9 & 6.4 \\
& $\mathrm{n}$ & 71 & 106 & 177 \\
Secondary & $\%$ & 51.1 & 61.6 & 56.9 \\
& $\mathrm{n}$ & 33 & 36 & 69 \\
College & $\%$ & 23.7 & 20.9 & 22.2 \\
& $\mathrm{n}$ & 32 & 13 & 45 \\
Total & $\%$ & 23.0 & 7.6 & 14.5 \\
& $\mathrm{n}$ & 139 & 172 & 311 \\
& $\%$ & 100.0 & 100.0 & 100.00 \\
\hline
\end{tabular}

$\mathrm{p}=0.018 ; 95 \%$ CI: -2.2 to -23.0$)$ but increased the lack of appetite score by 13.7 units $(\mathrm{t}=2.39 ; \mathrm{p}=0.018 ; 95 \% \mathrm{CI}$ : 2.4 to 24.9 ). The multiple regression models also showed that tumor location accounted for some of the differences in quality of life scores on the following domains: overall quality of life, physical performance, the functional role, emotional function, cognitive function, fatigue, nausea/vomiting, pain, lack of appetite, and diarrhea. In the multivariate models, sex significantly explained the variability in quality of life scores in the following domains: physical performance, emotional function, cognitive function, fatigue, nausea/vomiting, pain, and lack of appetite, with higher scores observed among women.

The DIF analysis, conducted by stratifying patients into only two clinical status categories (I to IIA $v s$. IIB to IV), showed that $66.2 \%(n=96)$ of the patients with colorectal cancer and $58.1 \%$ of the patients with gastric cancer were at the more advanced stage of the disease $(p>0.05)$. The graphical analysis showed that, when applying a t-value criterion greater than $|2| \mathrm{t}$, none of the items exhibited DIF when the data were stratified into two clinical categories (25). This finding suggests that for any of the staging groups, patients with high levels of quality of life tended to have higher scores on the scale.

In the DIF analysis that used tumor location as the staging criterion, more than one-third of the items on the scale (11 in total) exhibited differential functioning between the two cancer types: q10: Did you need to stop to rest?, q12: Have you felt weak?, q14: Have you felt nauseated?, q15: Have you vomited?, q18: Were you tired?, q20: Have you had difficulty in concentrating on things?, q21: Did you feel tense?, q23: Did you feel irritable?, q27: Has your physical condition interfered with your social activities?, q29: How would you rate your overall health during the past week?, and q30: How would you rate your overall quality of life during the past week? (Fig. 1). This finding suggests how these items might discriminate among the various intensities of the attribute (quality of life) between the two groups.

Regarding the persons-items mapping (Fig. 2), this sample exhibited a lower intensity for the attribute than the

Table II. Distribution of patients according to clinical stage and type of cancer

\begin{tabular}{lcccc}
\hline Stage & & Colorectal & Gastric & Total \\
\hline I & & 15 & 31 & 44 \\
& $\%$ & 10.3 & 18.0 & 14.5 \\
II & $\mathrm{n}$ & 40 & 41 & 81 \\
& $\%$ & 27.6 & 23.8 & 25.6 \\
& $\mathrm{n}$ & 56 & 52 & 108 \\
IV & $\mathrm{n}$ & 38.6 & 30.2 & 34.1 \\
& $\mathrm{n}$ & 34 & 48 & 82 \\
Total & $\%$ & 23.5 & 27.9 & 25.9 \\
& $\mathrm{n}$ & 145 & 172 & 317 \\
& $\%$ & 100.0 & 100.0 & 100.00 \\
\hline
\end{tabular}


Table III. Mean (SD) scores on the domains of the EORTC QLQ C30 scale according to location and clinical stage

\begin{tabular}{|c|c|c|c|c|c|c|}
\hline \multirow[t]{2}{*}{ Domain } & \multicolumn{2}{|c|}{ Location } & \multicolumn{4}{|c|}{ Clinical stage } \\
\hline & Colorectal & Gastric & 1 & II & III & IV \\
\hline Global & $74.1(21.0)^{\star *}$ & $61.5(21.8)$ & $70.2(20.9)$ & $67.2(22.5)$ & $66.9(22.6)$ & $66.1(22.6)$ \\
\hline Physical & $83.1(20.9) \star *$ & $75.8(24.4)$ & $81.8(23.9)$ & $81.8(21.5)$ & $80.6(21.3)$ & $72.9(25.6)$ * \\
\hline Functional role & $78.6(30.9)$ ** & $68.2(36.8)$ & 77.5 (36.5) & $75.9(32.8)$ & $72.2(34.7)$ & $68.5(35.0)$ \\
\hline Emotional & $77.4(23.3) \star *$ & $59.1(34.8)$ & $65.2(37.4)$ & $69.0(32.8)$ & $69.5(27.7)$ & $64.5(31.2)$ \\
\hline Cognitive & $85.6(19.9)^{\star *}$ & 72.5 (29.9) & $73.5(28.2)$ & $76.9(27.9)$ & $79.7(26.2)$ & $81.3(24.9)$ \\
\hline Social & $81.9(27.1)$ & $82.1(28.9)$ & $88.7(25.3)$ & $84.1(25.6)$ & $81.4(28.4)$ & $77.0(30.7)^{*}$ \\
\hline Fatigue & $23.6(25.5)^{\star *}$ & $44.5(30.8)$ & $31.8(31.8)$ & $35.6(29.7)$ & $35.1(31.2)$ & $35.9(29.1)$ \\
\hline Nausea/vomiting & $5.1(10.6)^{* *}$ & $17.3(26.2)$ & $11.2(19.8)$ & $9.4(19.7)$ & $13.4(23.1)$ & $12.2(21.7)$ \\
\hline Pain & $27.9(30.9)^{\star *}$ & $40.3(32.1)$ & $31.8(33.4)$ & $35.6(33.8)$ & $34.2(31.0)$ & 35.7 (31.7) \\
\hline Dyspnea & $10.3(20.9)$ & $14.3(24.9)$ & $11.5(23.5)$ & $14.4(26.3)$ & $11.1(24.1)$ & $13.0(18.7)$ \\
\hline Insomnia & $24.1(33.4)^{* *}$ & $32.7(38.4)$ & $30.4(40.8)$ & $25.5(33.0)$ & $27.4(36.1)$ & 32.9 (37.5) \\
\hline Lack of appetite & $11.2(23.3)^{\star *}$ & $23.2(36.2)$ & $8.7(22.7)$ & $15.2(26.3)$ & $23.1(37.9) *$ & $18.2(30.1)$ \\
\hline Constipation & $12.6(24.5)$ & $18.4(31.6)$ & $14.4(27.8)$ & $9.0(21.7)$ & $16.9(29.0)$ & $21.5(33.6)$ \\
\hline Diarrhea & $11.2(22.9)$ & $16.2(28.9)$ & $13.0(25.8)$ & $17.7(29.3)$ & $13.2(26.1)$ & $11.7(24.2)$ \\
\hline Financial & $36.3(36.4)$ & 40.7 (39.5) & $38.4(38.4)$ & $40.8(38.6)$ & $35.4(37.3)$ & $41.0(38.9)$ \\
\hline
\end{tabular}

*Significant difference, taking stage I as reference. **Significant difference between the two types of cancer.

Table IV. Regression coefficients for the multivariate model with domains of the EORTC QLQ C30 scale

\begin{tabular}{|c|c|c|c|c|c|c|c|c|c|c|c|c|c|c|c|c|c|c|}
\hline \multirow[b]{3}{*}{ Stage II } & \multicolumn{3}{|c|}{$\begin{array}{c}\text { General health } \\
\text { status }\end{array}$} & \multicolumn{3}{|c|}{$\begin{array}{c}\text { Physical } \\
\text { functioning }\end{array}$} & \multicolumn{3}{|c|}{$\begin{array}{l}\text { Functional } \\
\text { role }\end{array}$} & \multicolumn{3}{|c|}{$\begin{array}{l}\text { Emotional } \\
\text { functioning }\end{array}$} & \multicolumn{3}{|c|}{$\begin{array}{c}\text { Cognitive } \\
\text { functioning }\end{array}$} & \multicolumn{3}{|c|}{$\begin{array}{c}\text { Social } \\
\text { functioning }\end{array}$} \\
\hline & \multirow{2}{*}{$\frac{\text { Coef. }}{-5.3}$} & \multicolumn{2}{|c|}{ IC 95\% } & \multirow{2}{*}{$\frac{\text { Coef. }}{-2.3}$} & \multicolumn{2}{|c|}{ IC 95\% } & \multirow{2}{*}{$\frac{\text { Coef. }}{-3.7}$} & \multicolumn{2}{|c|}{ IC 95\% } & \multirow{2}{*}{$\frac{\text { Coef. }}{-2.2}$} & \multicolumn{2}{|c|}{ IC 95\% } & \multirow{2}{*}{$\frac{\text { Coef. }}{-1.3}$} & \multicolumn{2}{|c|}{ IC 95\% } & \multirow{2}{*}{$\frac{\text { Coef. }}{-5.5}$} & \multicolumn{2}{|c|}{ IC 95\% } \\
\hline & & -13.4 & 2.8 & & -10.8 & 6.3 & & -16.7 & 9.2 & & -13.4 & 9.1 & & -10.9 & 8.2 & & -16.1 & 5.1 \\
\hline Stage III & -6.0 & -13.8 & 1.7 & -3.7 & -11.9 & 4.5 & -7.2 & -19.6 & 5.2 & -2.5 & -13.2 & 8.3 & 1.1 & -8.0 & 10.2 & -8.4 & -18.5 & 1.7 \\
\hline Stage IV & -5.7 & -13.7 & 2.3 & -10.5 & -19.0 & -2.1 & -10.7 & -23.5 & 2.1 & -4.8 & -15.9 & 6.2 & 4.6 & -4.8 & 14.0 & -12.6 & -23.1 & -2.2 \\
\hline Location & -12.5 & -17.6 & -7.4 & -6.0 & -11.4 & -0.6 & -8.2 & -16.3 & 0.0 & -17.8 & -24.9 & -10.8 & -11.9 & -17.8 & -5.9 & -1.1 & -7.7 & 5.6 \\
\hline Sex & 0.1 & -4.8 & 5.0 & 5.3 & 0.1 & 10.5 & 3.4 & -4.5 & 11.3 & 12.5 & 5.6 & 19.3 & 13.3 & 7.5 & 19.0 & 3.3 & -3.1 & 9.7 \\
\hline No schooling & -8.5 & -20.3 & 3.3 & -12.2 & -24.7 & 0.2 & -18.5 & -37.3 & 0.4 & -7.1 & -23.4 & 9.3 & -10.1 & -23.9 & 3.7 & 5.2 & -10.2 & 20.5 \\
\hline $\begin{array}{l}\text { Primary } \\
\text { schooling }\end{array}$ & 0.0 & -7.3 & 7.3 & -6.2 & -13.9 & 1.5 & -8.1 & -19.8 & 3.6 & -3.9 & -14.0 & 6.2 & -7.9 & -16.5 & 0.7 & 6.3 & -3.3 & 15.8 \\
\hline $\begin{array}{l}\text { Secondary } \\
\text { schooling }\end{array}$ & -2.1 & -10.3 & 6.2 & -6.3 & -15.0 & 2.3 & -8.5 & -21.7 & 4.7 & -10.7 & -22.2 & 0.7 & -9.8 & -19.4 & -0.1 & 5.4 & -5.3 & 16.2 \\
\hline
\end{tabular}

Table V. Regression coefficients of the multivariate model with symptoms assessed by the EORTC QLQ C30 scale

\begin{tabular}{|c|c|c|c|c|c|c|c|c|c|c|c|c|c|c|c|}
\hline \multirow[b]{3}{*}{ Stage II } & \multicolumn{3}{|c|}{ Fatigue } & \multicolumn{3}{|c|}{ Nausea/vomiting } & \multicolumn{3}{|c|}{ Pain } & \multicolumn{3}{|c|}{ Lack of appetite } & \multicolumn{3}{|c|}{ Diarrhea } \\
\hline & \multirow{2}{*}{$\begin{array}{c}\text { Coef. } \\
9,4\end{array}$} & \multicolumn{2}{|c|}{$95 \% \mathrm{Cl}$} & \multirow{2}{*}{$\frac{\text { Coef. }}{2,3}$} & \multicolumn{2}{|c|}{$95 \% \mathrm{Cl}$} & \multirow{2}{*}{$\begin{array}{c}\text { Coef. } \\
8,3\end{array}$} & \multicolumn{2}{|c|}{$95 \% \mathrm{Cl}$} & \multirow{2}{*}{$\frac{\text { Coef. }}{11,4}$} & \multicolumn{2}{|c|}{$95 \% \mathrm{Cl}$} & \multirow{2}{*}{$\frac{\text { Coef. }}{6,1}$} & \multicolumn{2}{|c|}{$95 \% \mathrm{Cl}$} \\
\hline & & $-1,3$ & 20,0 & & $-5,4$ & 10,0 & & $-3,6$ & 20,2 & & 0,0 & 22,9 & & $-3,7$ & 15,8 \\
\hline Stage III & 9,4 & $-0,8$ & 19,6 & 6,7 & $-0,6$ & 14,1 & 7,4 & $-4,0$ & 18,7 & 20,4 & 9,4 & 31,3 & 2,9 & $-6,4$ & 12,2 \\
\hline Stage IV & 7,5 & $-3,0$ & 18,0 & 4,1 & $-3,5$ & 11,7 & 7,1 & $-4,6$ & 18,8 & 13,7 & 2,4 & 25,0 & $-0,4$ & $-10,0$ & 9,3 \\
\hline Location & $-20,4$ & $-27,1$ & $-13,8$ & $-13,1$ & $-17,9$ & $-8,2$ & $-12,5$ & $-19,9$ & $-5,0$ & $-13,4$ & $-20,6$ & $-6,3$ & $-7,7$ & $-13,8$ & $-1,6$ \\
\hline Sex & $-9,9$ & $-16,3$ & $-3,4$ & $-5,0$ & $-9,7$ & $-0,3$ & $-9,0$ & $-16,2$ & $-1,8$ & $-11,0$ & $-18,0$ & $-4,1$ & $-5,3$ & $-11,2$ & 0,6 \\
\hline No schoolling & 14,9 & $-0,6$ & 30,4 & 4,9 & $-6,3$ & 16,1 & 13,6 & $-3,7$ & 30,8 & 7,3 & $-9,3$ & 23,9 & $-16,4$ & $-30,5$ & $-2,2$ \\
\hline Primary schoolling & 3,4 & $-6,2$ & 13,0 & $-6,4$ & $-13,3$ & 0,5 & $-2,3$ & $-13,0$ & 8,4 & 0,2 & $-10,1$ & 10,5 & $-5,5$ & $-14,3$ & 3,2 \\
\hline Secundary schoolling & 3,4 & $-7,4$ & 14,2 & $-1,9$ & $-9,7$ & 6,0 & 3,3 & $-8,7$ & 15,4 & 5,0 & $-6,6$ & 16,6 & $-6,5$ & $-16,4$ & 3,4 \\
\hline
\end{tabular}

mean detected by the scale (i.e., the map shows that the mean for "persons" is lower than the mean for 'items'). Two items (q29: How would you rate your overall health during the past week? and q30: How would you rate your overall quality of life during the past week?) were stronger markers of the attribute (i.e., only those patients with very 


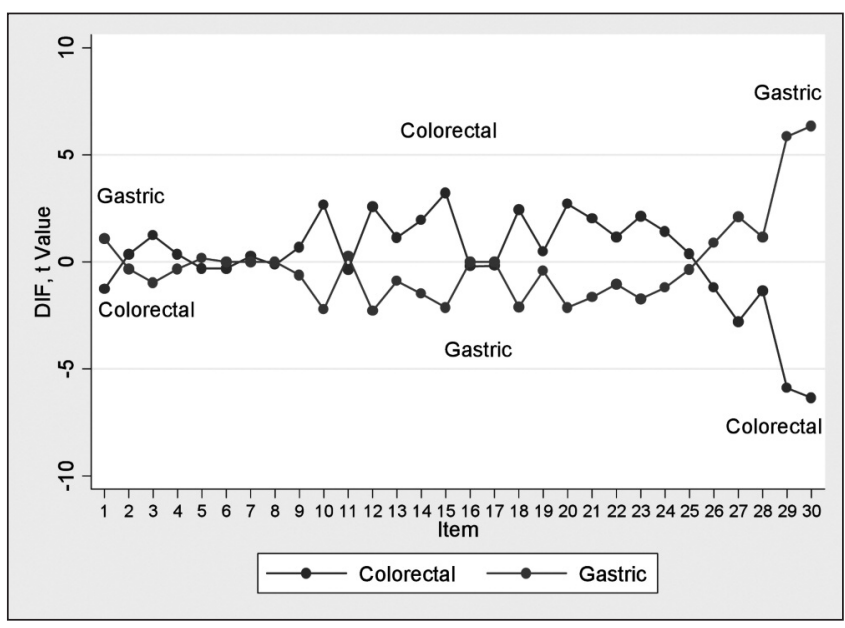

Fig. 1. DIF graph according to tumor location.

good quality of life reported high scores for these items). In contrast, one item (q5: Do you need help with eating, dressing, washing yourself or using the toilet?) was rated similarly among patients with good and bad quality of life.

\section{DISCUSSION}

This study compared quality of life scores in a group of patients with gastrointestinal cancer who were classified according to their clinical status. Among the 15 domains assessed by the quality of life scale used for the analysis, significant differences were only found in domains addressing physical and emotional functioning as well as only one symptom (lack of appetite). The use of analysis methods based on item response theory is justified by the fact that properties such as unidimensionality and invariance of these models allow for determining differential item functioning (DIF) in distinct subgroups (26). This feature allows researchers to establish whether observed differences correspond to the properties of the measuring instrument or to the characteristics of the patients. An item presents DIF when two comparable groups of subjects, i.e., groups that have the same level of the attribute measured by the test, report different scores for the item in question. If the presence of DIF is confirmed, it is possible to conclude that either differing intensities of the attribute exist among the groups or the items behave differently in distinct groups after controlling for general differences among the subgroups in the concept being measured (27). DIF thus makes it possible to determine whether the items on the quality of life scale behave in the same way in different patient subgroups; i.e., we would not expect different scores among patient subgroups who share the same level of quality of life. This methodology also allows for the identification of items that more adequately measure high levels of the attribute (26). In the present study, we hypothesized that quality of life levels varied according to clinical status, not tumor location.

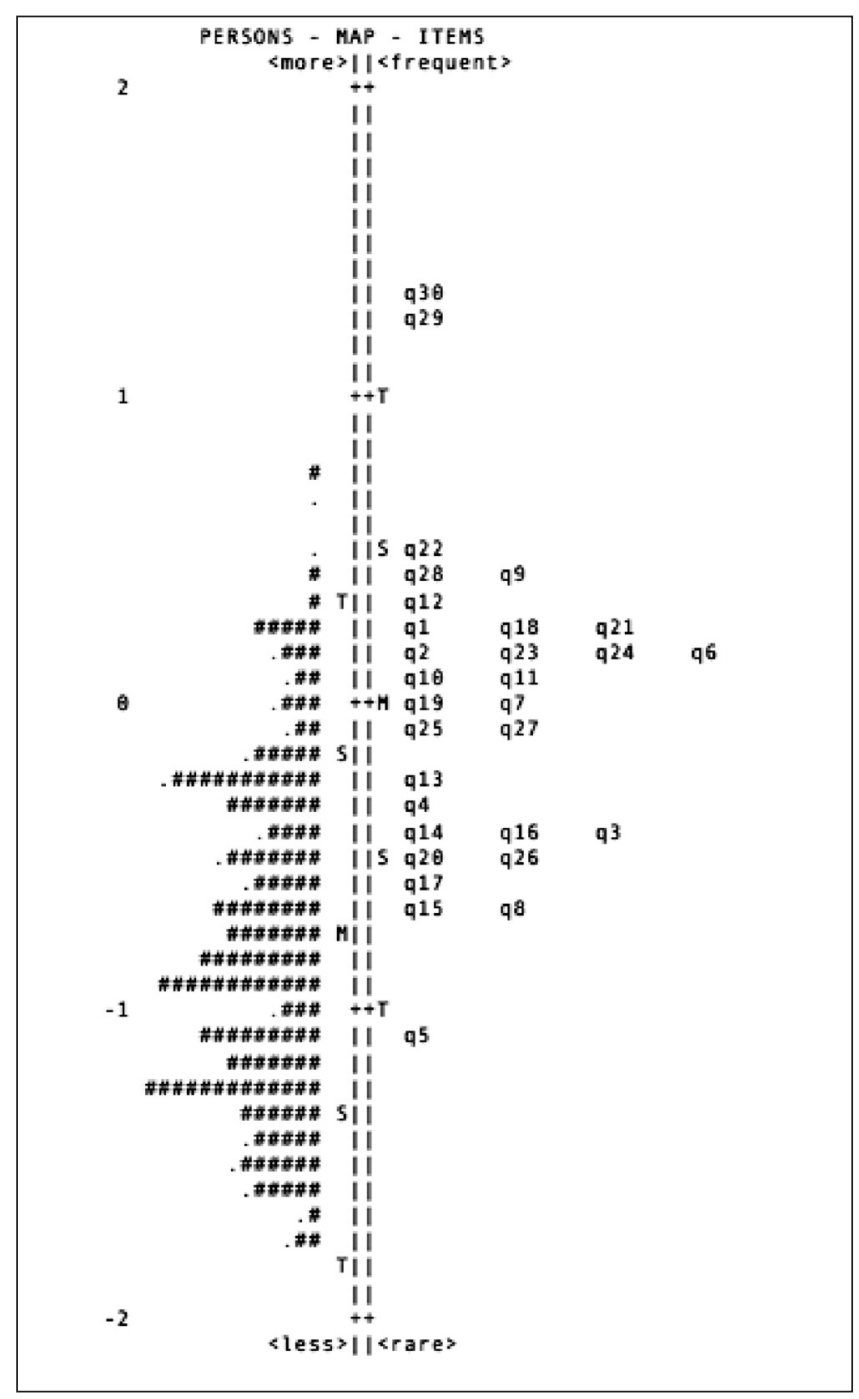

Fig. 2. Person-items maps. The distribution of patients is represented on the left side, with each \# representing two patients and each dot representing one patient. The distribution of items is represented on the right side (q1 to q30). The middle shows the location of the mean (M) and standard deviation ( $S=1 S D, T=2 S D$ ). Both the difficulty of the items and the magnitude of the persons' attribute are measured in the same dimension (logits).

It was first verified that the items of the questionnaire were not functioning poorly (i.e., there was no DIF according to clinical status), and the results suggested that the majority of the domains assessed by the scale were not strongly influenced by clinical status. It should be noted that the quality of life in these patients was more heavily affected by limitations of physical functioning (ability to perform activities such as going shopping, talking a walk, or moving) or social functioning (involvement in social and family life) than by the presence of symptoms. Indeed, patients at an advanced stage may have symptoms that do not significantly affect their quality of life, as suggested in other studies in which patients who sought medical advice at a later stage blamed their digestive symptoms on age or 
unhealthy eating habits (28). These results suggest that early diagnosis programs should have an educational dimension that encourages subjects to act earlier, when seemingly harmless symptoms arise. Another reason why we observed no differences in quality of life depending on clinical status could be related to mechanisms of psychological adaptation to the disease. However, the fact that the patients were all in the diagnostic phase of the process, independent of their clinical status, makes this interpretation of the results less convincing. The fact that only a few domains of the measuring instrument were different between groups raises the question of whether it is useful to generate global scores for these scales: if all the domains are grouped into a single score, the quality of the measures might be doubted because only some of the latent variables detect the attribute.

The results of this study also suggest that when assessing quality of life as an objective in intervention studies, the location of the tumor should be taken into account because in some cases, including gastric cancer, a measure with a greater effect could be expected. One of the clinical implications of these findings is that studies of gastric cancer patients should focus more heavily on the psychosocial, functional, and emotional aspects, regardless of clinical status, as the quality of life in these patients seems to be worse than in patients with colorectal cancer.

The fact that the best markers of quality of life In the study were items with a more general scope (q29: How would you rate your overall health during the past week? and q30: How would you rate your overall quality of life during the past week?) indicates the value of applying individualized methods instead of standardized instruments to measure quality of life $(8,29,30)$.

The difference in tumor location between socioeconomic groups (gastric cancer is more common in lower classes, whereas colorectal cancer is more common in upper classes) has been noted in previous studies conducted in Latin American populations (31). Although average patient age was rather low in both groups evaluated in the present study, previous studies in Latin America have reported similar results, especially for gastric cancer (32). Regarding the age of colorectal cancer patients, the potential for selection bias cannot be discounted, given that elderly patients could have been excluded for not complying with the reading and writing ability criterion.

The present study also found that women generally reported higher quality of life scores. This trend was also observed in previous studies, suggesting that men are less prone to accept and adapt to a cancer diagnosis (33), whereas women may be more disposed to discuss or express their feelings about matters related to adapting and facing the disease (34). However, this explanation might have a contradictory effect because of the greater ability of women to communicate and share personal information could also be expressed by higher scores on quality of life scales (35). This finding suggests that in clinical practice, it may be necessary to more deeply explore aspects related to quality of life among men than among women.
The limits of the present study can be summarized as follows.

1. The time of evolution of the symptoms was not taken into account. This variable could have introduced a major bias in the results.

2. It is possible that the findings were influenced by variables related to the independence of measures between patients at different clinical stages; thus, a prospective study that tests the same patients at different stages of the disease could limit the sources of bias.

3. Although efforts were made to assess a conditionspecific instrument, differences between the various stages could be detected when disease-specific scales were used (EORTC QLQ STO 22 and EORTC QLQ CR29). We note that the previously mentioned limits should be taken into account when designing future studies on the quality of life of patients suffering from cancer.

In conclusion, differences in quality of life that could be attributed to clinical status were only found in three domains (physical functioning, social functioning, and lack of appetite) of the EORTC QLQ C30. Most of the detected differences in quality of life were instead related to the location of the tumor (i.e., patients with colorectal cancer had a better quality of life than those with gastric cancer) and sex (women reported a better quality of life than men). The questionnaire items that best measured quality of life in these patients were those that explored the concept from a more general perspective, arguing for the use of individualized instruments instead of standardized scales.

\section{ACKNOWLEDGEMENTS}

Funding for this study was provided by the National University of Colombia and the National Institute of Oncology of Colombia.

\section{REFERENCES}

1. Jocham HR, Dassen T, Widdershoven G, Halfens R. Quality of life in palliative care cancer patients: a literature review. J Clin Nurs 2006; $15: 1188-95$.

2. Carr AJ, Gibson B, Robinson PG. Measuring quality of life: Is quality of life determined by expectations or experience? BMJ 2001; 19;322:1240-3

3. Macduff C. Respondent-generated quality of life measures: useful tools for nursing or more fool's gold? J Adv Nurs 2000;32:375-82.

4. Aaronson NK. Assessing the quality of life of patients in cancer clinical trials: Common problems and common sense solutions. Eur J Cancer 1992;28A:1304-7.

5. Kiebert GM, Curran D, Aaronson NK. Quality of life as an endpoint in EORTC clinical trials. European Organization for Research and Treatment for Cancer. Stat Med 1998; 17:561-9.

6. Smith KW, Avis NE, Assmann SF. Distinguishing between quality of life and health status in quality of life research: a meta-analysis. Qual Life Res 1999;8:447-59.

7. Albrecht GL, Devlieger PJ. The disability paradox: high quality of life against all odds. Soc Sci Med 1999;48:977-88. 
8. Skevington SM. Measuring quality of life in Britain: introducing the WHOQOL-100. J Psychosom Res 1999;47:449-59.

9. Higginson IJ, Carr AJ. Measuring quality of life: Using quality of life measures in the clinical setting. BMJ 2001;322:1297-300.

10. Webster K, Cella D, Yost K. The Functional Assessment of Chronic Illness Therapy (FACIT) Measurement System: properties, applications, and interpretation. Health Qual Life Outcomes 2003;1:79.

11. Osoba D, Zee B, Pater J, Warr D, Kaizer L, Latreille J. Psychometric properties and responsiveness of the EORTC quality of Life Questionnaire (QLQ-C30) in patients with breast, ovarian and lung cancer. Qual Life Res 1994;3:353-64.

12. Arraras JI, Suarez J, Arias de la Vega F, Vera R, Asin G, Arrazubi V, et al. The EORTC Quality of Life questionnaire for patients with colorectal cancer: EORTC QLQ-CR29 validation study for Spanish patients. Clin Transl Oncol 2011;13:50-6.

13. Blazeby JM, Conroy T, Bottomley A, Vickery C, Arraras J, Sezer O, et al. Clinical and psychometric validation of a questionnaire module, the EORTC QLQ-STO 22, to assess quality of life in patients with gastric cancer. Eur J Cancer 2004;40:2260-8.

14. Griffin AM, Butow PN, Coates AS, Childs AM, Ellis PM, Dunn SM, et al. On the receiving end. V: Patient perceptions of the side effects of cancer chemotherapy in 1993. Ann Oncol 1996;7:189-95.

15. Bramston P, Chipuer H, Pretty G. Conceptual principles of quality of life: an empirical exploration. J Intellect Disabil Res 2005;49:728-33.

16. O'Connell KA, Skevington SM. The relevance of spirituality, religion and personal beliefs to health-related quality of life: themes from focus groups in Britain. Br J Health Psychol 2005; 10:379-98.

17. Sanchez-Pedraza R, Ballesteros MP, Anzola JD. Concepto de calidad de vida en mujeres con cáncer. Rev Salud Publica (Bogota) 2010;12:889-902.

18. Carr AJ, Higginson IJ. Are quality of life measures patient centred? BMJ 2001;322:1357-60.

19. Chambers SK, Meng X, Youl P, Aitken J, Dunn J, Baade P. A fiveyear prospective study of quality of life after colorectal cancer. Qual Life Res 2012; 21:1551-64.

20. Mickeviciene A, Vanagas G, Ulys A, Jievaltas M, Smailyte G, Padaiga Z. Factors affecting health-related quality of life in prostate cancer patients. Scand J Urol Nephrol 2012;46:180-7.

21. (IARC) IAfRoC, (WHO) WHO. Globocan 2008: Cancer incidence and mortality worldwide in 2008. Lyon: IARC; 2008.

22. Piñeros M, Pardo C, Gamboa O, Hernández G. Atlas de mortalidad por cáncer en Colombia. Social MdlP, editor. Bogotá: Instituto Nacional de Cancerología; 2010.
23. Sánchez R, Venegas M, Otero J, Sánchez O. Adaptación transcultural de dos escalas para medir la calidad de vida en pacientes con cáncer en Colombia:EORTC QLQ-C30 y QLQ-BR23. Revista Colombiana de Cancerología 2009;13:205-12.

24. Teresi JA, Fleishman JA. Differential item functioning and health assessment. Qual Life Res 2007;16 (Supl. 1):33-42.

25. Wang WC. Assessment of differential item functioning. J Appl Meas 2008;9:387-408.

26. Fayers PM, Machin D. Quality of life: the assessment, analysis, and interpretation of patient-reported outcomes. 2nd ed. Chichester; Hoboken, NJ: J. Wiley; 2007.

27. Holland PW, Thayer DT. Differential Item Performance and the Mantel-Haenszel Procedure [microform]. [Washington, D.C.]: Distributed by ERIC Clearinghouse; 1986.

28. Delaney BC. Why do dyspeptic patients over the age of 50 consult their general practitioner? A qualitative investigation of health beliefs relating to dyspepsia. Br J Gen Pract 1998;48:1481-5.

29. Bernheim JL. How to get serious answers to the serious question: "How have you been?": subjective quality of life (QOL) as an individual experiential emergent construct. Bioethics 1999;13:272-87.

30. Chambers LW, Macdonald LA, Tugwell P, Buchanan WW, Kraag G. The McMaster Health Index Questionnaire as a measure of quality of life for patients with rheumatoid disease. J Rheumatol 1982;9: $780-4$.

31. Torres-Cintron M, Ortiz AP, Ortiz-Ortiz KJ, Figueroa-Valles NR, PerezIrizarry J, Diaz-Medina G, et al. Using a socioeconomic position index to assess disparities in cancer incidence and mortality, Puerto Rico, 1995-2004. Prev Chronic Dis 2012;9:E15.

32. Mendoza D, Herrera P, Gilman RH, Lanfranco J, Tapia M, Bussalleu A, et al. Variation in the prevalence of gastric cancer in Peru. Int J Cancer 2008;123:414-20.

33. Grube M. Compliance and coping potential of cancer patients treated in liaison-consultation psychiatry. Int J Psychiatry Med 2006;36: 211-29.

34. Grant M, McMullen CK, Altschuler A, Mohler MJ, Hornbrook MC, Herrinton LJ, et al. Gender differences in quality of life among longterm colorectal cancer survivors with ostomies. Oncol Nurs Forum 2011;38:587-96.

35. Perez Lara FJ, Navarro Pinero A, de la Fuente Perucho A. Study of factors related to quality of life in patients with locally advanced rectal cancer. Rev Esp Enferm Dig 2004;96:746-57. 